\title{
Middle Fossa Approach for Resection of an Intracanalicular Vestibular Schwannoma
}

\author{
Walter C. Jean ${ }^{1} \quad$ Kyle Mueller ${ }^{2} \quad$ H. Jeffrey Kim $^{3}$ \\ ${ }^{1}$ Department of Neurosurgery, George Washington University, \\ Washington, District of Columbia, United States \\ 2 Department of Neurosurgery, Georgetown University, Washington, \\ District of Columbia, United States \\ ${ }^{3}$ Department of Otolaryngology, Georgetown University, \\ Washington, District of Columbia, United States
}

\begin{abstract}
Address for correspondence Walter $C$. Jean, MD, Department of Neurosurgery, George Washington University, 2150 Pennsylvania Avenue, Northwest 7th Floor, Washington, DC 20037, United States (e-mail: wjean@mfa.gwu.edu).
\end{abstract}

J Neurol Surg B 2019;80(suppl S3):S287.

\begin{abstract}
Keywords

- middle fossa

- vestibular schwannoma

- facial nerve

- vestibulocochlear nerve

Objective This video was aimed to demonstrate the middle fossa approach for the resection of an intracanalicular vestibular schwannoma.

Design Present study is a video case report.

Setting The operative video is showing a microsurgical resection.

Participant The patient was a 59-year-old man who presented with worsening headache and right-side hearing loss. He was found to have a right intracanalicular vestibular schwannoma. After weighing risks and benefits, he chose surgery to remove his tumor. Since his hearing remained "serviceable," a middle fossa approach was chosen.

Main Outcome Measures Pre- and postoperative patient photographs evaluated the muscles of facial expression as a marker for facial nerve preservation.

Results A right middle fossa craniotomy was performed which allowed access to the floor of the middle cranial fossa. The greater superficial petrosal nerve (GSPN) and arcuate eminence were identified. Using these two landmarks, the internal acoustic canal (IAC) was localized. After drilling the petrous bone, the IAC was unroofed. The facial nerve was identified by stimulation and visual inspection and the tumor was separated from it with microsurgical dissection. In the end, the tumor was fully resected. Both the facial and cochlear nerves were preserved. Postoperatively, the patient experienced no facial palsy and his hearing is at baseline.

Conclusion With radiosurgery gaining increasing popularity, patients with intracanalicular vestibular schwannomas are frequently treated with it, or are managed with observation. The middle fossa approach is therefore becoming a "lost art," but as demonstrated in this video, remains an effective technique for tumor removal and nerve preservation. The link to the video can be found at: https://youtu.be/MD6o3DF6jYg.
\end{abstract}

Conflict of Interest

None declared.

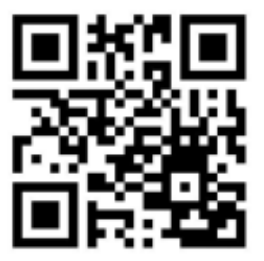

www.thieme.com/skullbasevideos

www.thieme.com/jnlsbvideos

received

May 29, 2018

accepted after revision

November 11, 2018

published online

March 7, 2019
DOI https://doi.org/

10.1055/s-0039-1677859.

ISSN 2193-6331.
๑) 2019 Georg Thieme Verlag KG
Stuttgart · New York

License terms

(c) (1) $\ominus$ (\$) 